\title{
DLA OBCEGO INNY GRÓB? WIELKOPOLSKIE GROBY TYPU BUSTUM JAKO PRZYKŁAD PRZYSWOJONEJ INNOŚCI RELIGIJNEJ
}

\author{
A GRAVE FOR AN ALIEN? GREATER POLAND GRAVES \\ OF TYPE BUSTUM AS AN EXAMPLE OF ASSIMILATED \\ RELIGIOUS OTHERNESS
}

\author{
Daniel Żychliński \\ APB THOR Sp. z o.o., Al. Reymonta 21 \\ 62-200 Gniezno, Polska \\ d.zychlinski@apbthor.pl
}

\begin{abstract}
ABSTACT: The paper is an attempt to present a model of an attitude towards strangers: getting to know, tolerating, accepting, and finally assimilating them, in terms of funeral rites, and thus of different religion. Such is a case manifested by an appearance of bustum type graves within the Przeworsk culture cemeteries in Wielkopolska (Greater Poland) in the Roman Iron Age.
\end{abstract}

KEY WORDS: cultural anthropology, funeral rites, bustum type graves, Roman Iron Age, Wielkopolska

Na cmentarzyskach ludności kultury przeworskiej oraz wielbarskiej pochodzących z Wielkopolski i datowanych na okres wpływów rzymskich wyróżniono osobną kategorię grobów, tzw. busta. Zagadnienie to było już przeze mnie analizowane przy okazji budowania hipotezy dotyczącej braku miejsc ciałopaleń tzw. ustryn w obrębie tych wielkopolskich nekropoli, gdzie przytoczyłem przykłady tego typu obiektów (Żychliński, 2013, s. 111-117). Wnioski powstałe na kanwie tamtejszych rozważań wskazywały, że jako miejsca kremacji błędnie interpretowano właśnie groby typu bustum. Natomiast ustryny musiały być lokowane poza strefą sacrum i profanum - w miejscu pomiędzy tymi dwoma porządkami ludzkiego życia (Żychliński, 2013, s. 113, 115, 116). Taki rozkład przestrzenny w pełni odpowiadał 
trójdzielnym rytuałom przejścia, w tym przypadku obrzędom pogrzebowym mającym na celu przeprowadzenie zmarłego z tego świata do świata duchowego i ponowne zasymilowanie osób dotkniętych jego śmiercią w tkankę żywej społeczności (van Gennep, 2006). W poprzednich rozważaniach pozwoliłem sobie bardzo ogólnikowo interpretować busta jako formę grobu zarezerwowaną dla „osób odgrywających znaczącą rolę w życiu społecznym lub rytualnym” (Żychliński, 2013, s. 116).

W niniejszym przyczynku chciałbym zwrócić uwagę na inną możliwość, zakładającą że pochowane w takich grobach osoby były „po prostu” obcego pochodzenia, a co za tym idzie, ich obrzędy pogrzebowe różniły się od panujących w okresie wpływów rzymskich w Wielkopolsce. Dlaczego jednak inni członkowie społeczności uszanowali te odmienne od swoich zasady? Przecież obrzędowość pogrzebowa jest dziedziną bardzo konserwatywną i trudno ulegającą przemianom (Niewęgłowski, 1981, s. 8-11 [tam też starsza literatura]). Jest to też jeden z najistotniejszych elementów tradycji (Sztompka, 2007, s. 249), tym samym silnie kultywowanym i niepoddającym się wpływom zewnętrznym. Obecność grobów typu bustum w nekropolach ludności przeworskiej i wielbarskiej „,w jawny sposób” naruszała konserwatyzm obu wyżej wymienionych elementów życia społeczności. I w tym miejscu pojawia się możliwość wytłumaczenia tego zjawiska na zasadzie akceptacji i może częściowego przyswojenia tych odmienności w lokalnym środowisku wielkopolskim.

W tym miejscu należy przedstawić charakterystykę obiektu-grobu, o którym mowa. Według definicji B. Józefów, która jako ostatnia prowadziła rozważania na temat tego typu obiektów cmentarzyskowych i zebrała znaczne spektrum literatury poświęconej temu zagadnieniu - bustum to: „obiekty przeznaczone na miejsca kremacji, które jednocześnie pełniły funkcję grobu. Były one używane jednorazowo, choć na jednym stosie i w tym samym czasie mogło być poddanych kremacji kilka ciał zmarłych" (Józefów, 2009, s. 544). Należy jednak podkreślić, że zainteresowanie bustami było do tej pory dość nikłe, choć nieliczni badacze obrządku pogrzebowego przejawiali je już znacznie wcześniej. O pozostawianiu ciałopalenia z resztkami stosu w miejscu dokonania kremacji w kontekście powstawania cmentarzysk warstwowych pisał już w 1965 roku J. Szydłowski (Szydłowski, 1965, s. 441), choć nie nazywał takich grobów bustami. Dopiero w ostatnim czasie omawianemu zagadnieniu poświęcono zdecydowanie więcej uwagi. Do zmiany wcześniejszego stanu rzeczy walnie przyczyniła się wspomniana wyżej B. Józefów, typologizując i definiując obiekty kremacyjne pochodzące z okresu wpływów rzymskich (Józefów, 2008), a następnie pogłębiając studia nad tym zagadnieniem (Józefów, 2009). Ostatnio też tematem pochówków typu bustum, w związku z ich powiązaniami z grobami warstwowymi i cmentarzyskami warstwowymi (typu dobrodzieńskiego), zainteresował się A. Błażejewski (Błażejewski, 2015, s. 207).

Na obszarach poza Barbaricum, na obszarach Imperium busta datuje się na I i II w. n.e. Znaleziska tego typu pochodzące z Galii sytuuje się w III w. n.e. Były też najczęściej odkrywane na cmentarzyskach o charakterze militarnym, co miało 
sugerować ich obcą w Imperium wschodnią genezę (Józefów, 2009, s. 547, 548; Błażejewski, 1998, s. 110, 111). Wzdłuż samego tylko Renu doliczono się ponad 50 stanowisk cmentarnych (Józefów, 2009, s. 548).

Busta wielkopolskie odkryte zostały zaledwie na 14 cmentarzyskach - 12 przynależnych ludności kultury przeworskiej i dwóch ludności wielbarskiej. Brak niestety możliwości uściślenia faktycznej ich liczby, jak i typu. Można jedynie przyjąć, że odsłonięto przynajmniej 6 bust powierzchniowych oraz kilkanaście jamowych na nekropolach przeworskich i dalszych, 4 jamowe i hipotetyczne pojedyncze powierzchniowe w obrębie cmentarzysk wielbarskich (Żychliński, 2013, s. 114, 115; Żychliński 2014, s. 86-88, 93, 94).

Za najstarszy można uznać grób ciałopalny nr 22 z Wymysłowa, pow. gostyński (Jasnosz, 1952, s. 12), który, jak wynika z opisu autora badań, może być reliktem bustum (które przyjęło postać grobu warstwowego), lecz nie ma całkowitej pewności. Założenie to datowane jest na fazę $\mathrm{A}_{3}$ młodszego okresu przedrzymskiego i charakteryzowało się bardzo dużymi rozmiarami (4,1 m długości), nieregularnym, płytkim przekrojem oraz równomiernie w warstwie rozproszonym ciałopaleniem. Wydaje się jednak, że znalezisko to można z pewną ostrożnością interpretować jako szczątki bustum bliżej niesprecyzowanej odmiany (Żychliński, 2014, s. 106). Obiekt ten swoją chronologią koresponduje z najwcześniejszymi bustami znanymi z obszarów Imperium Romanum (Józefów, 2009, s. 547)

Kolejne „przeworskie” groby omawianego typu pochodzą już z wczesnego okresu wpływów rzymskich (7). Na pojedynczy przykład natrafiono w Kunach, pow. turecki (ustryna $\mathrm{nr}$ 1). Jest on datowany na przełom stadiów $\mathrm{B}_{1}$ i $\mathrm{B}_{2}$ (Skowron, 2008, s. 96, 147). Dalsze 4 zespoły wystąpiły w Młodzikowie, pow. średzki (Dymaczewski, 1958, s. 291, 390). Obiekt nr 133 usytuowano w fazie $\mathrm{B}_{2 \mathrm{~b}}$, natomiast nr 256 rozdzielono na 3 groby, które nachodziły na siebie przestrzennie i sklasyfikowano w ramach stadium $\mathrm{B}_{1}$ (Żychliński, 2014, s. 118). Bardzo zbliżony morfologicznie grób nr 93 odkryty w Osieku, pow. Jarociński, datowany jest na fazę $\mathrm{B}_{2}$ (Pawlak, 2008, s. 309-311; 2011, s. 311). Ostatni zespół sytuowany we wczesnym okresie rzymskim to obiekt 155b pochodzący z Wymysłowa (Jasnosz, 1952, s. 95). Jego czas powstania określono na podfazę $\mathrm{B}_{2 \mathrm{~b}}$. Jak widać z przytoczonego po krótce zestawienia, można dostrzec wyraźny wzrost liczebności obiektów grobowych typu bustum rejestrowany na wielkopolskich cmentarzyskach ludności kultury przeworskiej w stosunku do okresu poprzedniego.

W odniesieniu do ludności wielbarskiej we wczesnym okresie wpływów rzymskich najprawdopodobniej można mówić tylko o pojedynczym przypadku hipotetycznego bustum powierzchniowego. Natrafiono na nie pod mogiłą II w Skórce, pow. złotowski (Karpińska, 1926, s. 19).

Przechodząc do późnego okresu wpływów rzymskich, można zarejestrować dalszy wzrost frekwencji bust w obrębie nekropoli ludności przeworskiej. W Ciążeńskich Holendrach, pow. słupecki (dawniej Ciążeń) (Ciesielski, 2015, s. 215), natra- 
fiono na przynajmniej kilka lub nawet kilkanaście obiektów, które można określić jako groby warstwowe, ponadto odnotowano także przepalenie podłoża (Zakrzewski, 1923, s. 97-99), co sugeruje, że były to najprawdopodobniej busta. Datuje się je ogólnie na późny okres rzymski. Groby warstwowe z tej nekropoli sytuuje się w przedziale od fazy $\mathrm{C}_{1 \mathrm{~b}}$ późnego okresu rzymskiego aż po $\mathrm{D}$ wczesnego okresu wędrówek ludów, jednak początki jej funkcjonowania sięgają wczesnego okresu rzymskiego (Ciesielski, 2015, s. 216). Podobną sytuację odnotowano także na cmentarzysku w Koninie, pow. loco, gdzie odsłonięto trudną do sprecyzowania, ale liczną grupę grobów warstwowych (Kostrzewski, 1947; Ciesielski 2015, s. 217-219), które można z pewną ostrożnością utożsamiać z grobami typu bustum. Sytuacja taka ma odniesienie na przykład do grobów nr 12-15 datowanych na fazę $\mathrm{C}_{2}$ późnego okresu wpływów rzymskich, $\mathrm{nr} 22\left(\mathrm{C}_{1 \mathrm{a}}\right), \mathrm{nr} 25\left(\mathrm{C}_{1}\right.$ ?) czy też $\mathrm{nr} 156$ zdeponowanego w stadium $\mathrm{C}_{1}$. Kilka dalszych zespołów pochodziło z Olbrachcic, pow. wschowski (Pfützenreiter, 1933, s. 68, 69, 70), które także można interpretować jako busta. Dotyczy to między innymi grobów nr 6, 8, 9, 13, 14 i 20 (Żychliński, 2014, s. 137), wszystkie jedynie ogólnie datowane na późny okres wpływów rzymskich. Podobnie przedstawia się obraz zastany na cmentarzysku w Wymysłowie, w odniesieniu do zespołów nr 42-43 $\left(\mathrm{C}_{1}\right), 193\left(\mathrm{C}_{1}\right.$ ?) (Jasnosz, 1952, s. 26, 134), które również z pewną ostrożnością można klasyfikować jako groby typu bustum (Żychliński, 2014, s. 137). Na nekropoli w Zapowiedni, pow. pyzdrski, nad której interpretacją nadal trwają intensywne prace (Ciesielski, 2015) można dopatrywać się dalszych przynajmniej kilkunastu bust, datowanych w ramach późnego okresu rzymskiego (Ciesielski, 213; 214). Przynajmniej pojedyncze bustum odnotowano najprawdopodobniej na cmentarzysku w Kocinie, pow. ostrowski (Błażejewski, 2007, s. 27; 2015, s. 205, 206; Józefów, 2008, s. 547). Ponadto również w południowej Wielkopolsce odkryto skupienie bust powierzchniowych przykrytych nasypami. Były to tzw. kurhany typu siedlemińskiego (Karpińska, 1926, s. 38-41; Józefów, 2008, s. 548), których zarejestrowano $9 \mathrm{w}$ ramach dość zwartego skupienia zlokalizowanego na południe od wsi Siedlemin (Żychliński, 2014, s. 134, 135).

W późnym okresie wpływów rzymskich odnotowano tylko pojedynczy przypadek i to dość niepewny grobu typu bustum w środowisku kultury wielbarskiej. Odkryto go na cmentarzysku w Słopanowie, pow. szamotulski - grób nr 54 (Przewoźna, 1955, s. 121; Żychliński, 2014, s. 145).

Zamykając powyższy przegląd, można dostrzec wzrost, i to znaczący, frekwencji grobów omawianego typu wraz z upływem czasu na wielkopolskich cmentarzyskach ludności kultury przeworskiej. Natomiast poziom ich obecności w nekropolach ludności wielbarskiej jest wręcz symboliczny. Biorąc pod uwagę, że przypadek ze Słopanowa budzi uzasadnione wątpliwości, można sugerować, że groby typu bustum nie występowały w ogóle na cmentarzyskach ludności kultury wielbarskiej w Wielkopolsce. Sytuację tę podkreślają dobrze rozpoznane i bardzo rozległe obiekty w typie Kowalewka (Skorupka, 2001), gdzie bust w ogóle nie zarejestrowano. 


\section{$* * *$}

Prowadząc dalej niniejsze rozważania, należy stwierdzić, że nie do końca można zgodzić się z sugestią wysuniętą przez B. Józefów, która zakładała, że pojawienie się bust na obszarze kultury przeworskiej było powiązane z infiltracją elementów obcych przez szlaki komunikacyjne i handlowe. Miejscowa ludność miałaby przejąć jedynie „techniczną”, a nie ideową stronę manifestowania się obcej obrzędowości pogrzebowej, na przykład w postaci ulepszeń konstrukcji stosu czy obcych elementów wyposażenia grobowego (Józefów, 2009, s. 548). Jakkolwiek nie można definitywnie odrzucać takiej interpretacji, to dość nieprawdopodobne wydaje się, w świetle wyżej podkreślanego konserwatyzmu obrzędowości pogrzebowej, przejmowanie różnorakich ,nowinek” bez dłuższej ich obserwacji i zaakceptowania przez daną społeczność, co nie mogło nastąpić jedynie na podstawie ,,przelotnych” spostrzeżeń.

Wydaje się, że bardziej zasadne byłoby tłumaczenie zachodzących zmian za pomocą hipotezy mówiącej o długotrwałym kontakcie ludności miejscowej i napływowej. Sytuacja taka mogłaby powstać w momencie sprowadzenia pewnej liczby obcych etnicznie osób, które zamieszkałyby z autochtonami. Można tu założyć uprowadzenie $\mathrm{z}$ terenów rodzimych i osadzenie w formie niewolników. Jednak, zgodnie z definicją niewolnictwa autorstwa L. Schumachera: „[...] w przypadku niewolnika mamy do czynienia z człowiekiem, który bezpośrednio poddany jest totalnej, tzn. nieograniczonej i nieustającej w czasie władzy swego pana" (Schumacher, 2005, s. 15) nie sposób zakładać, że niewolnik byłby traktowany na równi z wolnym członkiem społeczności i pochowano by go po śmierci zgodnie z wyznawanymi przez niego zasadami pogrzebu i do tego w przestrzeni sacrum wspólnotowego cmentarzyska. Osoby te zatem nie mogły być niewolnikami, którzy są pozbawieni wszelkich praw, w tym też i religijnych. Kto zatem chciałby przestrzegać obrządku i reguł pochówku wyznawanego przez niewolnika? Nikt!

Jednak sytuacja wyglądałaby zgoła odmiennie, gdyby przyjąć model wskazujący, że choć osoby takie zostały zawłaszczone i siłą przywiedzione na obszary Wielkopolski, z czasem uzyskałyby status ludzi wolnych i zaczęły swobodnie funkcjonować w ramach danej społeczności. Wtedy to miałyby okazję przedstawić „na forum" swoje zasady religijne, a co więcej, poprzez na przykład małżeństwo, mogłyby przekazać je autochtonom, a przede wszystkim swoim potomkom. Wydaje się, że w taki sposób można by tłumaczyć częściowo stopniowy, jak i momentami skokowy (późny okres wpływów rzymskich) wzrost wraz z upływem czasu liczby grobów typu bustum na wielkopolskich nekropolach ludności przeworskiej.

Obserwując wzrost frekwencji grobów typu bustum na cmentarzyskach przeworskich w Wielkopolsce, można posunąć się dalej i przedstawić hipotezę zakładającą wzrost ,zainteresowania” tą formą pochówku. Należy się jednak zastanowić, jaka była tego przyczyna. Można sugerować, że ,zainteresowanie” owo podyktowane było wydarzeniami mającymi miejsce $\mathrm{z}$ dala od omawianego terenu, wszak po- 
czątek późnego okresu wpływów rzymskich to czas niepokojów i wojen na limesie rzymskim - wojny markomańskie (por. Olędzki, 2015, s. 77-81). Dzięki takiej sytuacji polityczno-społecznej ,pozyskiwanie” znacznych zastępów niewolników nie nastręczało zapewne większych trudności. $Z$ pewnością o wiele trudniej było znaleźć na nich nabywców, zwłaszcza na obszarach głębokiego Barbaricum. Wydaje się, że wzrost frekwencji grobów typu bustum można wiązać ze znaczną liczbą osób, które ze statusu niewolnika przeznaczonego do sprzedaży, w związku z brakiem popytu, zostały „przygarnięte” przez wcześniejszych ciemiężycieli. Idąc dalej, można przyjąć, że wraz z upływem czasu zamieszkania osoby te zasymilowały się ze społecznościami, w których przebywały.

Odmiennie wydaje się przedstawiać sytuacja w odniesieniu do kurhanów typu siedlemińskiego, które wiązane są z ludnością przeworską (Skóra, 2010, s. 33; Żychliński, 2014, s. 39, 134, 135). Bazując na fakcie wydatkowania znacznych nakładów sił i środków na budowę mogił, można założyć, że pochowano w nich przedstawicieli lokalnych elit (Karpińska, 1926, s. 135; Skóra, 2010, s. 36). Nasuwa się pytanie, czy była to warstwa lokalnego, czy też obcego pochodzenia. Można jednak zakładać, że jej członkowie byli połączeni „więzami krwi” (Żychliński, 2014, s. 77). Jeśli nie byli autochtonami, swoje zwyczaje pogrzebowe przynieśli ze sobą i były one przestrzegane zarówno przez nich samych, jak i pozostałych członków społeczności, którymi władali. Ponieważ analogiczne założenia znane są z obszarów Germanii (Błażejewski, 2007, s. 30,31,160,161), być może właśnie w tych terenach należy dopatrywać się stron rodzinnych tych przybyszów. Natomiast, jeśli była to lokalna warstwa wyższa, mogła przyjąć „nowinki” pogrzebowe z obszarów Imperium Rzymskiego, aby odróżnić się od reszty grupy i dodatkowo utwierdzić swój wysoki status społeczny.

Zdecydowanie inaczej, jak to wynika z przedstawionego wyżej zestawienia znanych przypadków grobów typu bustum, wygląda sytuacja w środowisku kultury wielbarskiej w Wielkopolsce. Z dużą pewnością można przyjąć, że w ogóle nie spotyka się ich na nekropolach tej ludności. Wydaje się, że taka absencja może wskazywać, że ludność wielbarska nie miała dostępu do odmiennych nurtów światopoglądowych, co mogło być związane z jej brakiem zaangażowania w odległe terytorialnie konflikty. Jednak bardziej prawdopodobne wydaje się tłumaczenie, które wskazuje, że społeczności tego ugrupowania były zdecydowanie bardziej konserwatywne w zakresie obrzędowości pogrzebowej niż jej południowi sąsiedzi ludność przeworska. Konserwatyzm ten jest doskonale widoczny w powszechnie znanym „tabu” zakazującym umieszczania broni i narzędzi żelaznych w grobach (Skorupka, 2001, s. 242; Żychliński, 2014, s. 129, 147, 155, 156).

Chciałbym też nadmienić, że opisane i interpretowane przeze mnie zjawisko bynajmniej nie ogranicza się przestrzennie do Wielkopolski. Prowadząc dalsze badania, będzie można $\mathrm{z}$ łatwością wyróżnić je na pozostałych obszarach zajętych przez społeczności kultury przeworskiej i wielbarskiej. Nie bez znaczenia będą tu dalsze analizy poświęcone obecności i formie niewolnictwa we wzmiankowanych społecznościach. 
Natomiast, jak przedstawiono $\mathrm{w}$ zaprezentowanym modelu przyjęcia obcych wzorców społecznych dotyczących obrzędowości pogrzebowej, odpowiadając na postawione w tytule artykułu pytanie, można stwierdzić, że początkowo obcy element - przybysz, zostaje przyjęty w obręb społeczności, dalej stopniowo zaakceptowany wraz ze swoją odmiennością, a następnie zasymilowany z tą społecznością do takiego stopnia, że jego przekonania światopoglądowe, manifestujące się skrajnie różnym sposobem pogrzebu, stają się elementami obrzędowości funeralnej osób z tym obcym najbliżej powiązanych.

Kwestia obecności grobów typu bustum na cmentarzyskach przeworskich w Wielkopolsce może być też rozpatrywana jako przejaw tolerancji społecznej w stosunku do jednostek wyznających inną wiarę. Mimo głębokiego konserwatyzmu własnych wierzeń eschatologicznych, ludność przeworska zezwalała, zapewne po dłuższym okresie asymilacji, na pochówek w ramach przestrzeni sacrum wspólnotowego cmentarza, osób, które miały z pewnością odmienne wyznanie, a co za tym idzie - inne zwyczaje pogrzebowe. Groby typu bustum były diametralnie inne od dotychczas budowanych na nekropolach przeworskich, zaprzeczały wręcz rytuałom przejścia, ponieważ eliminowały strefę przejściową między sacrum a profanum.

Powyższe dywagacje trzeba opatrzyć pewnym zastrzeżeniem. Otóż należy przyznać, że przedstawiony model asymilacji obcego człowieka wraz z jego wierzeniami może być obarczony ogromnym błędem, ponieważ, jak zauważają niektórzy badacze przedmiotu, nasze obecne przekonania czy stereotypy kulturowe mogą nie mieć żadnego przełożenia na zasady i sposób myślenia ludzi w przeszłości (Gellner, 1982). Mimo to horyzonty pojęciowe obecnych społeczności zawierają elementy przeszłych horyzontów, co więcej, przecież z nich właśnie się wywodzą. Tak więc, działając na podstawie własnego aparatu pojęciowego, możemy budować modele przeszłości, która bynajmniej nie jest całkowicie oderwana od teraźniejszości (Gadamer, 2007, s. 415-417). Sam żywię jednak przekonanie o słuszności ostatniego $\mathrm{z}$ dwóch przedstawionych tu punktów widzenia.

Wydaje się zatem, że omawiane w niniejszym przyczynku zagadnienie jest bardzo intrygujące, a próby wyjaśnienia jego genezy mogą wnieść bardzo wiele w zakres rozważań o obrzędowości pogrzebowej w aspekcie społeczno-psychologicznym, a nie jedynie na płaszczyźnie materialnych jej manifestacji.

\section{BIBLIOGRAFIA}

Błażejewski A.

1998 Obrzadek pogrzebowy kultury przeworskiej na Dolnym Ślasku. Wrocław: Oficyna Wydawnicza Oddziału Wrocławskiego PTTK „Sudety”.

Błażejewski A. 
2007 Kultura przeworska a reńsko-wezerska strefa kulturowa. Wrocław: Wydawnictwo

Błażejewski A.

Uniwersytetu Wrocławskiego Sp. z o.o.

2015 W kwestii definicji grobów warstwowych z okresu rzymskiego. W: L. Tyszler, E. Droberjar (red.), Barbari superiores et inferiores. Archeologia Barbarzyńców 2014 (s. 199-209). Łódź - Wieluń.

Ciesielski M.

2015 Cmentarzyska „warstwowe” kultury przeworskiej w Wielkopolsce wschodniej. W: L. Tyszler, E. Droberjar (red.), Barbari superiores et inferiores. Archeologia Barbarzyńców 2014 (s. 211-223). Łódź - Wielun.

Dymaczewski A.

1958 Cmentarzysko z okresu rzymskiego w Młodzikowie, pow. Środa. Fontes Archaeologici Posnanienses, 8-9, s. 179-443.

Gadamer H.-G.

2007 Prawda i metoda. Zarys hermeneutyki filozoficznej. Warszawa: Wydawnictwo Naukowe PWN.

Gellner E.

1982 Relativism and universals. W: M. Hollis, S. Lukes (red.), Rationality and relativism (s. 181-200). London: Blackwell.

Gennep van A.

2006 Obrzędy przejścia. Warszawa: Państwowy Instytut Wydawniczy.

Jasnosz S.

1952 Cmentarzysko z okresu późnolateńskiego i rzymskiego w Wymysłowie, pow. Gostyń.

Fontes Praehistorici, 2, s. 1-282.

Józefów B.

2008 Typologia obiektów kremacji w okresie rzymskim. Na przykładach wybranych z terenów prowincji rzymskich i Barbaricum. W: J. Skowron; M. Olędzki (red.), Kultura przeworska. Odkrycia - Interpretacje - Hipotezy, 2 (s. 211-242). Łódź: Instytut Studiów

Józefów B. Międzynarodowych Wydział Studiów Międzynarodowych i Politologicznych UŁ.

2009 Problematyka badań miejsc kremacji. W: M. Karwowski, E. Droberjar (red.), Archeologia Barbarzyńców 2008. Powiąania i kontakty w świecie barbarzyńskim (s. 543-557). Rzeszów: Mitel.

Karpińska A.

1926 Kurhany z okresu rzymskiego w Polsce ze szczególnym uwzględnieniem typu siedlemiń-

Kostrzewski B.

skiego. Poznań: Poznańskie Towarzystwo Przyjaciół Nauk.

1947 Cmentarzysko z okresu rzymskiego w Koninie. Przeglad Archeologiczny, 7(2), s. 192-294.

Niewęgłowski A.

1981 Obrzadek pogrzebowy ludności kultury przeworskiej na przełomie er. Wrocław: Zakład Narodowy im. Ossolińskich, Wydawnictwo Polskiej Akademii Nauk.

Olędzki M.

2015 Inferiores barbarii: Markomanowie i Kwadowie. Krótki zarys dziejów. W: L. Tyszler, E. Droberjar (red.), Barbari superiores et inferiores. Archeologia Barbarzyńców 2014 (s. 73-87). Łódź - Wieluń.

Pawlak E.

2008 Cmentarzysko ludności kultury przeworskiej w Osieku, pow. Jarocin. W: H. Machajewski (red.), Wielkopolska w pradziejach. Archeologia o regionie (s. 207-213). Poznań.

Pawlak E. 
2011 Cmentarzysko ludności kultury przeworskiej w Osieku koło Jarocina. Wstępne wyniki badań. Wielkopolskie Sprawozdania Archeologiczne, 12, s. 295-315.

Pfützenreiter F.

1933 Die vor- und frügeschichtliche Besiedlung des Kreises Fraustadt. Schneidemühl.

Przewoźna K.

1955 Osada i cmentarzysko z okresu rzymskiego w Słopanowie, pow. Szamotuły. Fontes Archaeologici Posnanienses, 5, s. 60-139.

Schumacher L.

2005 Niewolnictwo antyczne. Dzień powszedni i los niewolników. Poznań: Wydawnictwo Poznańskie.

Skorupka T.

2001 Kowalewko 12. Cmentarzysko birytualne ludności kultury wielbarskiej (od połowy I w. n.e. do początku III w. n.e.). W: M. Chłodnicki (red.), Archeologiczne badania ratownicze wzdtuż trasy gazociagu tranzytowego, T. 2: Wielkopolska (cz. 3). Poznań: Wydawnictwo Poznańskie.

Skóra K.

2010 Intruz w kurhanie? O pochówkach wtórnych w obrzędowości pogrzebowej kultury wielbarskiej i przeworskiej. W: K. Skóra, T. Kurasiński (red.), Wymiary inności. Nietypowe zjawiska w obrzędowości pogrzebowej od pradziejów po czasy nowożytne (s. 27-43). Łódź: Łódzkie Towarzystwo Naukowe.

Sztompka P. 2007 Socjologia. Analiza społeczeństwa. Kraków: Znak.

Szydłowski J.

1965 Ze studiów nad ciałopalnym obrządkiem pogrzebowym kultury przeworskiej. Archeologia Polski, 9, s. 430-451.

Żychliński D.

2013 The Absence of Cremation Sites within Cemeteries of the Przeworsk and Wielbark Żychliński D. Cultures in the Roman Period in Great Poland. Sociology and Anthropology, 1, s. 111-117.

2014

Obrządek pogrzebowy ludności kultury przeworskiej $i$ wielbarskiej $w$ Wielkopolsce. Prace Archeologiczne 1. Zielona Góra-Gniezno: Fundacja Archeologiczna. Wydawnictwo Fundacji Archeologicznej.

\title{
A GRAVE FOR AN ALIEN GREATER POLAND GRAVES OF TYPE BUSTUM AS AN EXAMPLE OF ASSIMILATED RELIGIOUS INDIVIDUALITY
}

\author{
S u m m a r y
}

Within cemeteries of Przeworsk and Wielbark cultures in Greater Poland, dated to Roman period, a new category of graves was distinguished - bustum burials. This contribution will present the hypothesis, which explains that people buried in such type of graves were probably of foreign origin, and their funeral rites were different from local burial practices. However, we should con- 
sider why other members of the community respected funeral principles different from their own. All the more, the burial rite is an extremely conservative and hard changing area of human life.

It seems, that the facts known from cemeteries could be explained by the hypothesis of longlasting contact of the local population with the immigrants. Such a situation could arise, when a number of ethnically alien people lived for long time with natives. Foreign newcomers would have been admitted in the community, then gradually accepted together with their religious otherness, and in the end assimilated. In effect, their foreign funeral beliefs, manifested in extremely different burial rituals, have become elements of the funeral practices of some members of local community. The presence of bustum graves within Przeworsk culture cemeteries in Greater Poland, could also be seen as a sign of tolerance of the members of these societies, in relation to the people of foreign religion.

Further attempts to explain the origins of this phenomenon, could bring a lot to the discussion about the burial rite in socio-psychological aspect, not only in area of its material manifestation. 